\title{
Identification of Suspension Bridge Parameters under Exploitational Conditions
}

\author{
Joanna Iwaniec ${ }^{1}$ and Marek Iwaniec ${ }^{2}$ \\ 1. Department of Robotics and Mechatronics, Faculty of Mechanical Engineering and Robotics, AGH University of Science and \\ Technology, Krakow 30-059, Poland \\ 2. Department of Process Control, Faculty of Mechanical Engineering and Robotics, AGH University of Science and Technology,
} Krakow 30-059, Poland

Received: June 12, 2014 / Accepted: June 25, 2014 / Published: August 25, 2014.

\begin{abstract}
The paper concerns a research into dynamic properties of the steel suspension bridge across Opolska Street in Krakow, Poland. Parameter identification was carried out with the application of the nonlinear system identification method on the basis of system responses to exploitational excitation resulting from pedestrian traffic. In order to verify obtained results, on the basis of the geometrical and material properties of the considered system, the FEM (finite elements model) was created. Created FEM model was updated through the comparison with the model determined by the use of experimental modal analysis method and then applied to analytical evaluation of the considered suspension bridge natural frequencies.
\end{abstract}

Key words: Steel bridge, nonlinear system identification, exploitational excitation.

\section{Introduction}

While analyzing properties of mechanical systems working under operational loads, the measurement of forces exciting system vibrations is difficult or impossible to carry out directly. This issue is especially important in case of systems of significant mass or stiffness, which demand for energy necessary to excite motion with many mode shapes is too high to be realized with the use of standard equipment for structural dynamics testing. Moreover, the output-only identification methods known from literature and used in the engineering practice, find application to research into properties of linear systems only [1].

The paper concerns parameter identification of the suspension bridge on the basis of measured system responses to exploitational excitation with pedestrian traffic. The research was carried out with the use of method consisting in sequential application of restoring

Corresponding author: Joanna Iwaniec, Ph.D., research fields: modal analysis, nonlinear system identification and signal processing. E-mail: jiwaniec@agh.edu.pl. force, boundary perturbation and direct parameter identification techniques $[2,3]$. On the contrary to classical nonlinear system identification methods, the method requires neither the knowledge of excitation acting on the system nor system linear behaviour in the broad frequency range around an operating point. The method can be applied to both linearity testing and parameter identification of linear and nonlinear systems. Correctness of the experimental research was verified by analytical determination of natural frequencies and corresponding mode shapes with the use of the finite elements method.

The paper is organized as follows: Section 2 provides the theory of the applied methods; Section 3 concerns the results of the research into dynamic properties of the steel suspension bridge in Krakow, Poland; Section 4 gives conclusions.

\section{Identification of Nonlinear System Parameters}

Identification of the considered suspension bridge 
was performed by means of the output-only method combining restoring force, boundary perturbation and direct parameter estimation techniques (Fig. 1).

In the first step [2, 3], system dynamic motion equations are formulated and nonlinear restoring forces are estimated on the basis of measured system responses. In the following step, identified nonlinear restoring forces are eliminated from the formulated dynamic motion equations that describe the balance of forces acting on the considered system. Since the excitation remains unknown, the number of unknown parameters is greater than the number of dynamic motion equations that can be formulated. In order to provide an additional dynamic motion equation and determine absolute values of system parameters, the boundary perturbation method is used. The method consists in introducing an additional mass (inertia) altering dynamic behaviour of the considered system and retaking measurements of modified system masses accelerations. In the final step, values of system parameters are estimated.

Presented above method of nonlinear system parameters identification on the basis of measured system responses is a convenient parameter identification method for strongly nonlinear systems working under operational loads, the measurement of which is difficult or impossible to carry out $[5,6]$.

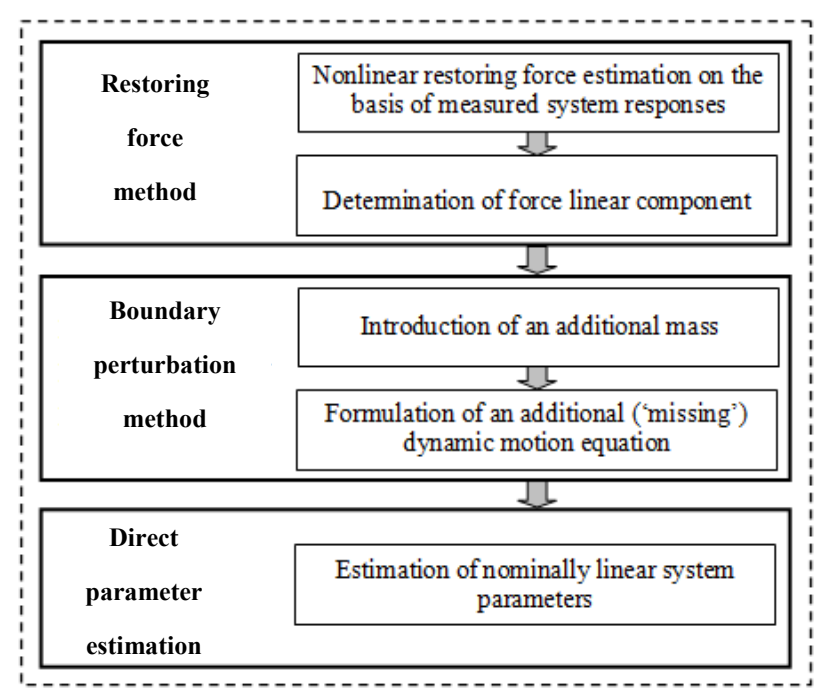

Fig. 1 Applied nonlinear system identification method [4].

\subsection{Restoring Force Method}

Restoring force method algorithm for single degree-of-freedom systems was formulated by Masri and Caughey in 1979 [7]. In the following years, the modified algorithms of the method were developed. These variations are referred to as force-state mapping $[8,9]$ and local restoring force method [10].

The method is based on the dynamic motion equation specified by the Newton's second law:

$$
M \cdot\{\ddot{x}(t)\}+\{f(\{x(t)\},\{\dot{x}(t)\})\}=\{u(t)\}
$$

where, $M$ denotes (effective) system mass; $\{u(t)\}$ : exciting force vector; $\{x(t)\},\{\dot{x}(t)\}$ : displacement and velocity of mass $M$; and $\{f(\{x(t)\},\{\dot{x}(t)\})\}$ : vector of internal restoring forces.

Since $\{f\}$ only depends on $\{x(t)\}$ and $\{\dot{x}(t)\}$, it can be represented by a surface over the $(x, \dot{x})$ state space:

$$
\{f(\{x(t)\},\{\dot{x}(t)\})\}=\{u(t)\}-M \cdot\{\ddot{x}(t)\}
$$

In practice, the measurements of vibration accelerations are performed while vibration velocities and displacements are determined by numerical time-domain integration of measured accelerations. If the measurements are taken at time intervals $t_{i}=(i-$ 1) $\Delta t$, Eq. (2) can be written as follows:

$$
\left.\left.\left\{f_{i}\right\}=\left\{f\left(\left\{x\left(t_{i}\right)\right)\right\}\left\{\dot{x}\left(t_{i}\right)\right)\right\}\right)\right\}=\left\{u\left(t_{i}\right)\right\}-M \cdot\left\{\ddot{x}\left(t_{i}\right)\right\}
$$

At each instant $i=1, \ldots, N$, the triplet $\left\{x\left(t_{i}\right)\right\},\left\{x^{\prime}\left(t_{i}\right)\right\}$, $f_{i}$ is specified. The first two values indicate the point in the phase plane while the third value specifies the distance between this point and the restoring force surface.

Masri and Caughey [11] proposed the method consisting in restoring force modelling by the use of the Chebyshev series:

$$
\{f(\{x\},\{\dot{x}\})\}=\sum_{i=0}^{m} \sum_{j=0}^{n} C_{i j} T_{i}(\{x\}) T_{j}(\{\dot{x}\})
$$

where, $T_{i}(x)$ denotes Chebyshev polynomial of the $i$ th order. 
For hysteretic systems, the internal restoring force does not depend entirely on system position in the phase plane. As an example, the Bouc-Wen model [12, 13] can be considered:

$$
\left\{\begin{array}{l}
M\{\ddot{x}\}+\{f(\{x\},\{\dot{x}\})\}+\{z\}=\{u(t)\} \\
\quad\{\dot{z}\}=-\alpha \mid\{\dot{x}\}\left\{\{z\}\{z z\}^{n-1}-\beta\{\dot{x}\}\left|\{z\}^{n}\right|+[A]\{\dot{x}\}\right.
\end{array}\right.
$$

In this case, the Chebyshev polynomials method cannot be used since the system internal restoring force is a function not only of $\{x\}$ and $\{\dot{x}\}$ but also $\{z\}$, so that a force surface over a phase plane is multivalued.

In Refs. [14, 15], the authors proposed to represent the hysteretic restoring force by the following equation:

$$
\{\dot{f}\}=g(\{f\},\{\dot{x}\})
$$

In such a case, the restoring force first derivative is represented by the surface over the plane $(f, \dot{x})$.

\section{Results of Operational Identification of Suspension Bridge Parameters}

Suspension bridge over Opolska Street in Krakow (Fig. 2) is a welded massive construction that could easily withstand motor traffic but is used as a footbridge only. Bridge platform of $4.64 \mathrm{~m}$ in width, consists of orthotropic reinforced concrete plate on the steel grate and two steel beams of dimensions $0.5 \times$ $0.86 \mathrm{~m}^{2}$ is hung from the steel A-type pylon $34.5 \mathrm{~m}$ high. The overall bridge span amounts to $120 \mathrm{~m}$.

Modal parameters of the considered suspension bridge estimated on the basis of transfer functions between excitation signal and system responses measured with the use of impulse test, which was carried out in the absence of pedestrian and vehicle traffic [17], are presented in Table 1 and Fig. 3.

In the course of the identification experiment, according to the scheme assumed during modal tests, the network of 14 measurement points (Fig. 4) was assumed: seven points along the left and seven points along the right footbridge edge (localized at the balustrade base).
In Table 2, there are presented coordinates of the consecutive measurement points.

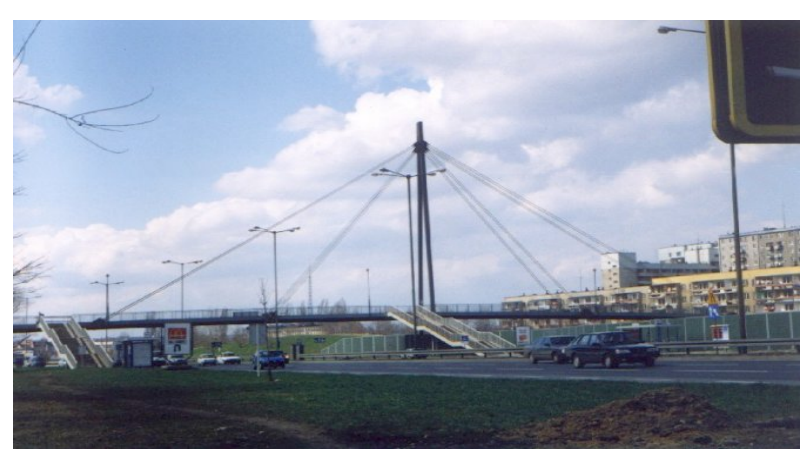

Fig. 2 Considered suspension bridge [16].

Table 1 Considered system natural frequencies and corresponding damping factors [17].

\begin{tabular}{llllll}
\hline No. & $f(\mathrm{~Hz})$ & $\zeta(\%)$ & No. & $f(\mathrm{~Hz})$ & $\zeta(\%)$ \\
\hline 1 & 2.78 & 0.94 & 10 & 9.64 & 0.77 \\
2 & 2.96 & 0.62 & 11 & 10.21 & 0.15 \\
3 & 3.25 & 0.86 & 12 & 11.20 & 0.19 \\
4 & 5.02 & 1.09 & 13 & 13.87 & 0.31 \\
5 & 5.64 & 0.93 & 14 & 16.03 & 0.61 \\
6 & 6.06 & 0.44 & 15 & 16.99 & 0.21 \\
7 & 6.27 & 1.03 & 16 & 18.49 & 0.34 \\
8 & 7.07 & 0.49 & 17 & 21.04 & 0.25 \\
9 & 8.92 & 0.10 & 18 & 23.33 & 0.13 \\
\hline
\end{tabular}

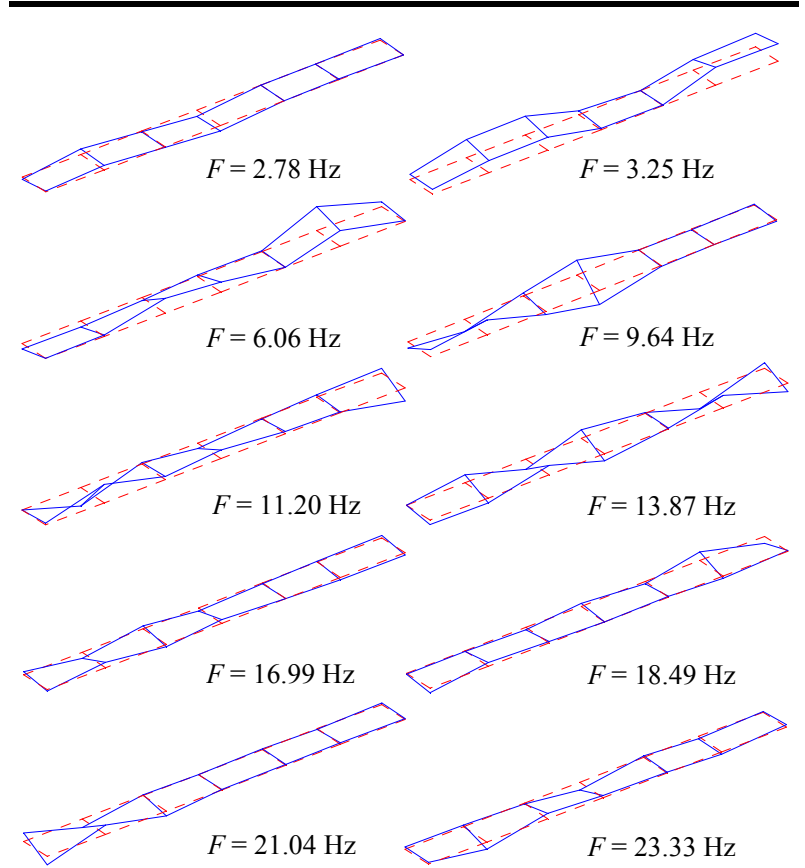

Fig. 3 Selected mode shapes of the considered suspension bridge [17] estimated with the application of the operational modal analysis. 


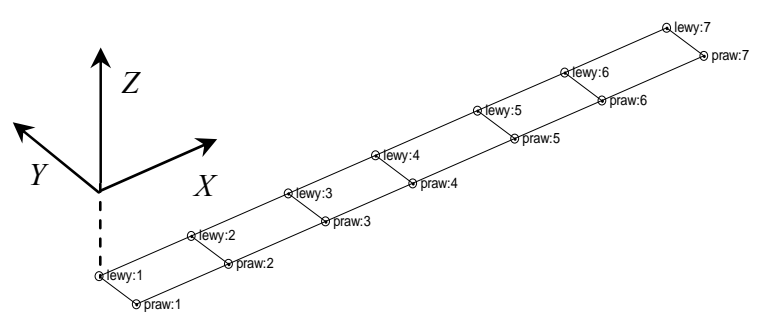

Fig. 4 Assumed network of measurement points.

Table 2 Location of the assumed measurement points.

\begin{tabular}{|c|c|c|c|c|c|}
\hline No. & $\begin{array}{l}\text { Point } \\
\text { name }\end{array}$ & $X(\mathrm{~m})$ & $Y(\mathrm{~m})$ & $Z(\mathrm{~m})$ & Description \\
\hline 1 & Lewy: 1 & 0.0 & 5.0 & 0.0 & $\begin{array}{l}\text { Point of the } 1 \text { st rope } \\
\text { fastening }\end{array}$ \\
\hline 2 & Lewy: 2 & 9.5 & 5.0 & 0.0 & $\begin{array}{l}\text { Between the } 1 \text { st and the } \\
\text { 2nd rope }\end{array}$ \\
\hline 3 & Lewy: 3 & 19.5 & 5.0 & 0.0 & $\begin{array}{l}\text { Point of the } 2 \text { nd rope } \\
\text { fastening }\end{array}$ \\
\hline 4 & Lewy: 4 & 28.5 & 5.0 & 0.0 & $\begin{array}{l}\text { Between the 2nd rope } \\
\text { and pylon }\end{array}$ \\
\hline 5 & Lewy: 5 & 39.0 & 5.0 & 0.0 & Pylon \\
\hline 6 & Lewy: 6 & 48.5 & 5.0 & 0.0 & $\begin{array}{l}\text { Between pylon and the } \\
\text { 3rd rope }\end{array}$ \\
\hline 7 & Lewy: 7 & 58.5 & 5.0 & 0.0 & $\begin{array}{l}\text { Point of the } 3 \text { rd rope } \\
\text { fastening }\end{array}$ \\
\hline 8 & Praw: 1 & 0.0 & 0.0 & 0.0 & $\begin{array}{l}\text { Point of the 1st rope } \\
\text { fastening }\end{array}$ \\
\hline 9 & Praw: 2 & 9.5 & 0.0 & 0.0 & $\begin{array}{l}\text { Between the } 1 \text { st and the } \\
\text { 2nd rope }\end{array}$ \\
\hline 10 & Praw: 3 & 19.5 & 0.0 & 0.0 & $\begin{array}{l}\text { Point of the } 2 \text { nd rope } \\
\text { fastening }\end{array}$ \\
\hline 11 & Praw: 4 & 28.5 & 0.0 & 0.0 & $\begin{array}{l}\text { Between the 2nd rope } \\
\text { and pylon }\end{array}$ \\
\hline 12 & Praw: 5 & 39.0 & 0.0 & 0.0 & Pylon \\
\hline 13 & Praw: 6 & 48.5 & 0.0 & 0.0 & $\begin{array}{l}\text { Between pylon and the } \\
\text { 3rd rope }\end{array}$ \\
\hline 14 & Praw: 7 & 58.5 & 0.0 & 0.0 & $\begin{array}{l}\text { Point of the } 3 \text { rd rope } \\
\text { fastening }\end{array}$ \\
\hline 15 & Base & 0.0 & 0.0 & 0.0 & - \\
\hline
\end{tabular}

Measurements of vibration accelerations in vertical direction were carried out in the points "praw: 1", "praw: 3", "praw: 5" and "base" by means of the uniaxial piezoelectric accelerometer of the PCB 393A03 type.

Measured time histories were registered with the use of the 8-channel SCADAS Mobile analyzer. It was also assumed that estimation of the considered system parameters will be carried out with the use of the operational identification method presented in the second paragraph of this paper. Therefore, two measurement sessions were carried out. In the second session, the bridge was loaded with the additional mass $\Delta M_{\mathrm{Z}}$. Acceleration time histories measured in the considered measurement points are presented in Fig. 5.

In the course of the considered system parameters identification process, discrete 2-degrees-of-freedom model (Fig. 6) was used. The following notation was assumed: $M_{1}$ denotes reduced mass of bridge support; $M_{Z}$ : reduced mass in the point of rope fastening; $K_{2}$ : stiffness of bridge span; $K_{1}$ : stiffness of bridge support; $C_{2}$ : bridge span damping coefficient; $C_{1}$ : bridge support damping coefficient; $x_{1}, x_{2}, x_{b}$ : displacements of $M_{1}, M_{Z}$ and base; $N_{1}, N_{2}$ : nonlinear forces.

Dynamic motion equations formulated for system reduced masses $M_{1}$ and $M_{\mathrm{Z}}$ are as follows:

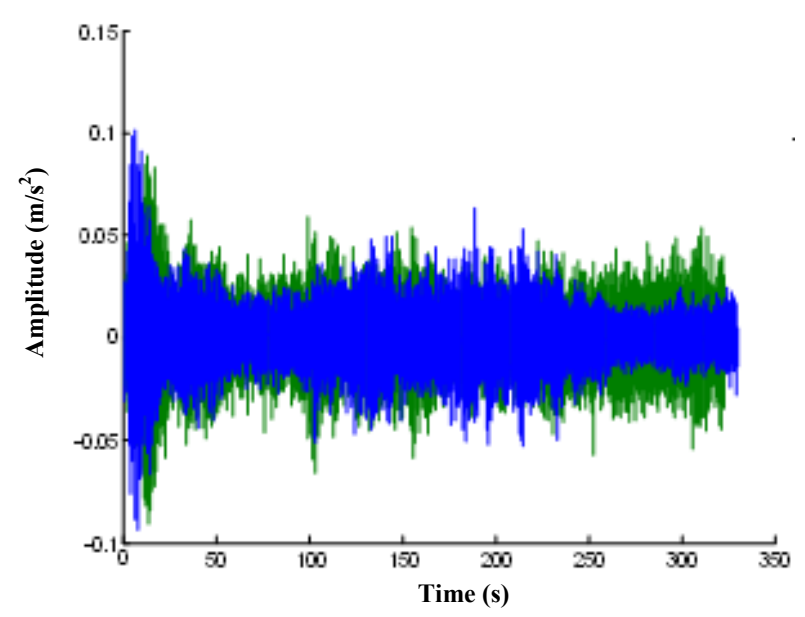

(a)

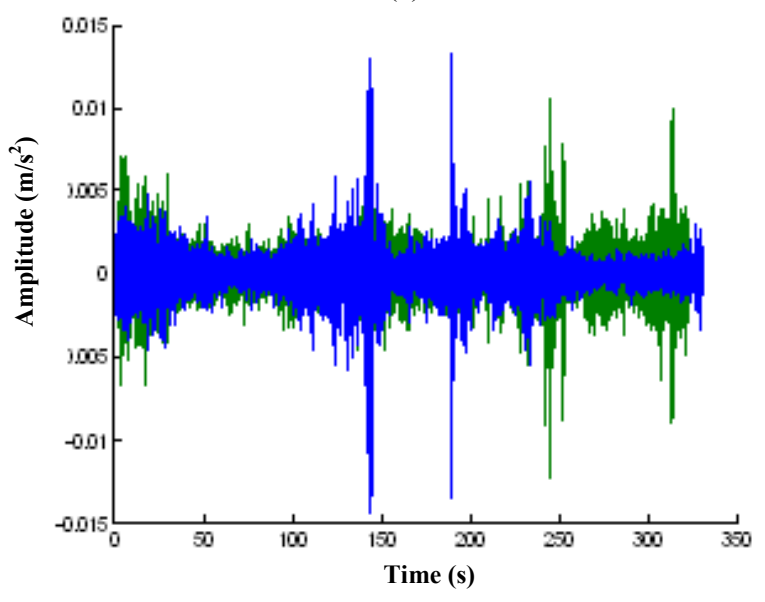

(b)

Fig. 5 Acceleration time histories in points (a) "praw: 3" and (b) "base" measured in the first (-) and the second (-) measurement session. 


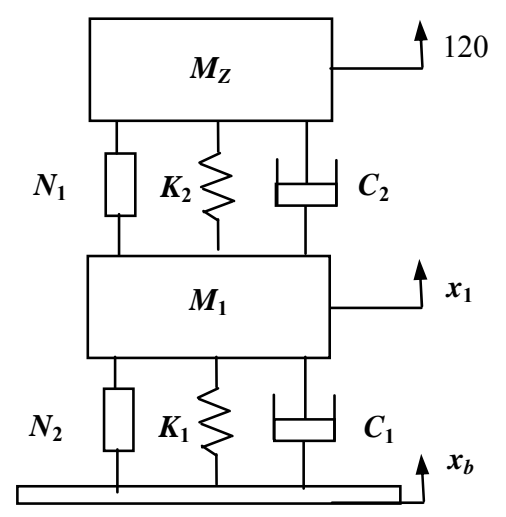

Fig. 6 Discrete model of the considered system.

$$
\left\{\begin{array}{l}
M_{1}\left\{\ddot{x}_{1}\right\}+\left(C_{1}+C_{2}\right)\left\{\dot{x}_{1}\right\}-C_{2}\left\{\dot{x}_{2}\right\}+K_{1}\left\{x_{1}\right\}+ \\
+K_{2}\left\{x_{1}\right\}-K_{2}\left\{x_{2}\right\}+N_{1}+N_{2}=C_{1}\left\{\dot{x}_{b}\right\}+K_{1}\left\{x_{b}\right\} \\
M_{Z}\left\{\ddot{x}_{2}\right\}-C_{2}\left\{\dot{x}_{1}-\dot{x}_{2}\right\}-K_{2}\left\{x_{1}\right\}+ \\
+\left(K_{2}+K_{3}\right)\left\{x_{2}\right\}=N_{1}+\left\{F_{Z}\right\} \\
\left\{x_{1}\right\}=\left\{x_{1}(t)\right\},\left\{x_{2}\right\}=\left\{x_{2}(t)\right\}, \\
N_{1}=N_{1}\left(\left\{x_{1}\right\},\left\{x_{2}\right\},\left\{\dot{x}_{1}\right\},\left\{\dot{x}_{2}\right\}\right), \\
N_{2}=N_{2}\left(\left\{x_{1}\right\},\left\{x_{b}\right\},\left\{\dot{x}_{1}\right\},\left\{\dot{x}_{b}\right\}\right) .
\end{array}\right.
$$

Dynamic motion equation for $M_{z}$, is transformed to the following form:

$$
\begin{aligned}
M_{Z}\left\{\ddot{x}_{2}\right\} & =-C_{2}\left\{\dot{x}_{2}-\dot{x}_{1}\right\}-K_{2}\left(\left\{x_{2}\right\}-\left\{x_{1}\right\}\right)+ \\
& +N_{1}+\left\{F_{Z}\right\}
\end{aligned}
$$

Relations between acceleration of mass $M_{\mathrm{Z}}$ and relative velocity; between masses $M_{1}$ and $M_{Z}$; between acceleration of the mass $M_{\mathrm{Z}}$ and relative displacement; as well as between masses $M_{1}$ and $M_{Z}$, were determined.

In order to reconstruct restoring forces acting on the considered system, on the basis of measured acceleration time histories, time histories of velocities and displacements in the considered measurement points were determined. On the basis of relation between acceleration of $M_{\mathrm{Z}}$ in the function of relative velocity of masses $M_{1}$ and $M_{\mathrm{Z}}$, and relation between acceleration of $M_{Z}$ and relative displacement of masses $M_{1}$ and $M_{Z}$, it was assessed that the character of damping and stiffness restoring forces is linear (Fig. 7).

Therefore, the next step of the assumed identification method (consisting in estimation of parametric models $f_{N}$ of identified nonlinear forces and their elimination

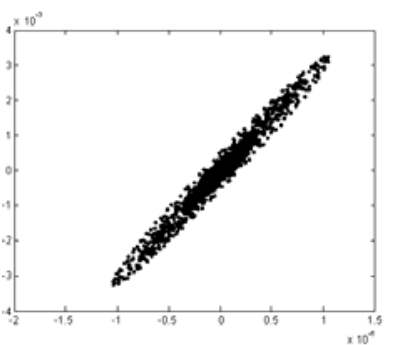

(a)

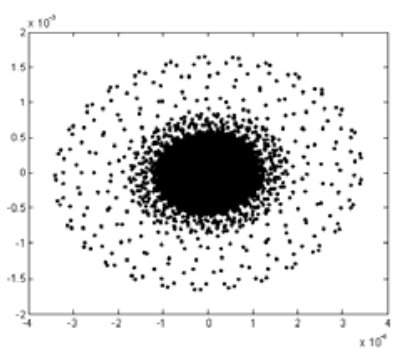

(b)
Fig. 7 Example reconstructed (a) stiffness and (b) damping restoring forces.

from dynamic motion equation formulated for mass $M_{Z}$ ) was neglected:

$$
\left\{\ddot{x}_{2}\right\}-f_{N}=\frac{C_{2}}{M_{Z}}\left(\left\{\dot{x}_{1}\right\}-\left\{\dot{x}_{2}\right\}\right)+\frac{K_{2}}{M_{Z}}\left(\left\{x_{1}\right\}-\left\{x_{2}\right\}\right)+\frac{\left\{F_{Z}\right\}}{M_{Z}}
$$

On the basis of the considered system discrete model, with the use of the direct parameter identification method, the following equations were formulated:

$$
\left\{\begin{array}{l}
K_{2}\left(1-\frac{1}{T_{21}\left(\omega_{k}\right)}\right)=\omega_{k}^{2} M_{Z} \\
T_{21}(0)=K_{2}\left(K_{2}+K_{1}\right)^{-1}, \quad k=1,2, \ldots, N_{f}
\end{array}\right.
$$

where, $\left\{T_{21}(j \omega)\right\}=\left\{X_{2}(j \omega)\right\}\left\{X_{1}(j \omega)\right\}^{-1}$ : transmissibility function between displacements of masses $M_{Z}$ and $M_{1}$ (determined after elimination of nonlinear restoring forces $\left.f_{N}\right) ; X_{1}(j \omega), X_{2}(j \omega)$ : Fourier transforms of signals $x_{1}(t)$ and $x_{2}(t) ; N_{f}$ : number of identified degrees of freedom; and $T_{21}(0)$ : value of $\left\{T_{21}(j \omega)\right\}$ for $f=0 \mathrm{~Hz}$.

Since the measurement of exact bridge elements mass values is impossible to carry out, the system in Eq. (10) is a system of two equations with three unknowns: $M_{\mathrm{Z}}, K_{2}$ and $K_{1}$.

In the second measurement session, system dynamic behaviour was modified by loading the bridge platform with an additional mass. For the modified system, according to the algorithm of the boundary perturbation method, the measurements of system masses vibration accelerations were repeated. As a result of system modification, Eq. (10) can be written as follows:

$$
K_{2}\left(1-\frac{1}{T_{21}\left(\omega_{p}\right)}\right)=\omega_{p}^{2}\left(M_{Z}+\Delta M_{Z}\right)
$$

where, $\left\{T_{21}{ }^{\prime}(j \omega)\right\}$ : transmissibility function between 
displacements of masses $\left(M_{\mathrm{Z}}+\Delta M_{\mathrm{Z}}\right)$ and $M_{1}, p=1$, $2, \ldots, N_{f}$.

Eqs. (10) and (11) form a system of three equations with three unknowns, which makes it possible to estimate absolute values of the required system parameters.

In Fig. 8, there is presented comparison of determined transmissibility functions $\left\{T_{21}\right\}$ and $\left\{T_{21}{ }^{\prime}\right\}$ between displacements in points "praw: 3" and "base".

The results presented below were estimated for transfer functions $\left\{T_{21}\right\}$ and $\left\{T_{21}^{\prime}\right\}$ determined between points "praw: 3" (point of the second line fastening) and "base". For the purposes of determining maxima of transfer functions $\left\{T_{21}\right\}$ and $\left\{T_{21}{ }^{\prime}\right\}$, the stabilization diagrams method (Fig. 9) realized with the use of the ERA (eigensystem realisation algorithm) method implemented in the VIOMA (virtual in-operation modal analysis toolbox) was used. Magnitudes corresponding to the consecutive maxima of the considered transfer functions were determined with the application of the Signal Processing toolbox. Obtained results were used as a basis for computations of the considered system required parameters.

As the measure of system parameters estimation accuracy, the relative percentage error of the reduced mass $M_{Z}$ estimation was assumed:

$$
\operatorname{Err}=\left(M_{Z}^{M E S}\right)^{-1} \cdot\left|M_{Z}^{M E S}-M_{Z}^{e}\right| \cdot 100 \cdot[\%]
$$

where, $M_{z}^{M E S}$ denotes mass determined on the basis of the formulated FEM model; and $M_{z}^{e}$ : mass estimated with the use of the operational identification method.

In Table 3, there are presented values of the considered suspension bridge parameters estimated with the application of the operational identification method and relative percentage errors of mass $M_{Z}$ estimated for the consecutive extremes of transfer functions. Parameters corresponding to the extremes of transfer functions $\left\{T_{21}\right\}$ and $\left\{T_{21}{ }^{\prime}\right\}$, for which pole lines determined with the use of stabilization diagrams (Fig. 9) are stabilizing, are marked in grey.
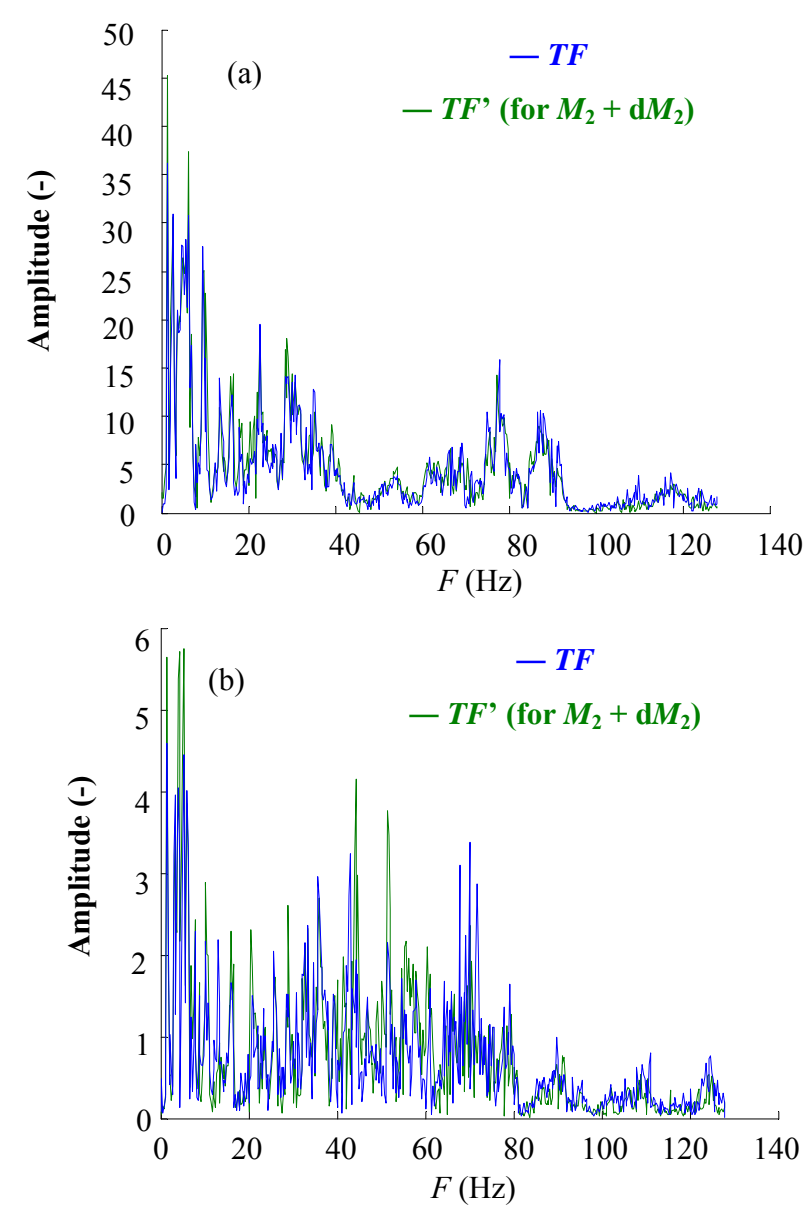

Fig. 8 Comparison of transfer functions: (a) $\left\{T_{21}\right\}_{2}$ line-base and $\left\{T_{21}\right\}_{2 \_ \text {line-base }}$, (b) $\left\{T_{21}\right\}_{\text {pylon-base }}$ and $\left\{T_{21}\right\}_{\text {pylon-base }}$

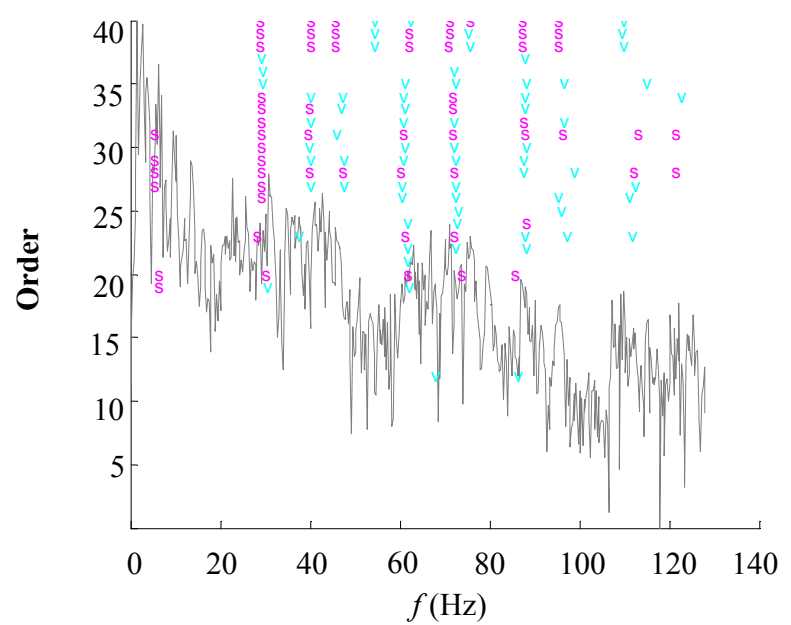

Fig. 9 Example of stabilization diagram (estimated for transfer functions $\left\{T_{21}\right\}_{2}$ rope-base $)$. 
In order to verify the correctness of the obtained results, on the basis of the geometrical and material properties [16], the FEM (finite elements model) of the considered suspension bridge was created (Figs. 10 and 11). Computations were carried out in the Strand7 software [18]. Created FEM was updated through the comparison with model determined by the use of experimental modal analysis method [17] and then applied to analytical evaluation of the considered suspension bridge natural frequencies.

Table 3 Parameters of transfer functions, estimated model parameters, percentage relative error.

\begin{tabular}{llllllll}
\hline No. $\omega(\mathrm{Hz})$ & $T_{21}(\omega)$ & $\begin{array}{l}\omega^{\prime} \\
(\mathrm{Hz})\end{array}$ & $T_{21}{ }^{\prime}(\omega)$ & $\begin{array}{l}M_{Z}^{e} \\
(\mathrm{~kg})\end{array}$ & $10^{3}$ & $\operatorname{Err}(\%)$ \\
\hline 1 & 1.50 & 36.1574 & 1.50 & 45.1786 & 683.8892 & 269.7 \\
2 & 2.75 & 30.8497 & 2.75 & 30.6031 & 12621.76 & $6,722.6$ \\
3 & 3.75 & 21.0406 & 3.75 & 20.1296 & 192.0703 & 3.8 \\
4 & 4.75 & 27.6815 & 4.25 & 20.4249 & 234.849 & 26.9 \\
5 & 5.75 & 28.2772 & 5.5 & 26.3638 & 193.3022 & 4.5 \\
6 & 6.25 & 30.7916 & 6.25 & 37.3069 & 169.3744 & -8.4 \\
7 & 7.00 & 17.2791 & 7.00 & 18.5328 & 173.5164 & -6.2 \\
8 & 9.50 & 27.5478 & 9.75 & 25.0533 & 196.869 & 6.4 \\
9 & 10.25 & 16.0256 & 10.25 & 22.7646 & 140.4449 & -24.1 \\
10 & 13.50 & 13.9085 & 13.50 & 10.9267 & 281.953 & 52.4 \\
11 & 16.25 & 12.2613 & 16.00 & 14.1146 & 155.4952 & -15.9 \\
12 & 18.00 & 8.8135 & 18.00 & 9.6580 & 155.9759 & -15.7 \\
13 & 18.50 & 6.0253 & 18.50 & 9.2229 & 84.16074 & -54.5 \\
14 & 22.75 & 19.538 & 22.75 & 19.4115 & 186.178 & 0.6 \\
15 & 28.50 & 14.1120 & 28.50 & 16.8444 & 154.1666 & -16.7 \\
16 & 30.75 & 14.2798 & 30.75 & 13.5544 & 198.0801 & 7.1 \\
17 & 31.75 & 11.2387 & 31.75 & 11.1093 & 188.6531 & 2.0 \\
18 & 35.50 & 12.8411 & 35.25 & 10.4371 & 271.1228 & 46.6 \\
19 & 39.25 & 7.0916 & 39.25 & 9.1178 & 114.1498 & -38.3 \\
20 & 42.25 & 3.1264 & 41.75 & 2.3841 & -91.5741 & -149.5 \\
21 & 51.25 & 2.7156 & 51.25 & 2.7680 & 148.4777 & -19.7 \\
22 & 61.75 & 5.7512 & 61.00 & 4.9006 & 513.5548 & 177.6 \\
23 & 68.75 & 6.8484 & 68.50 & 5.8130 & 386.5977 & 109.0 \\
24 & 69.25 & 7.2044 & 69.25 & 5.2234 & -4613.79 & $-2,593.9$ \\
25 & 71.25 & 3.7376 & 71.25 & 3.3946 & 639.1044 & 245.5 \\
26 & 75.00 & 10.5100 & 75.50 & 8.4672 & 318.2946 & 72.1 \\
27 & 77.75 & 15.8281 & 77.25 & 14.2626 & 210.2761 & 13.7 \\
28 & 81.75 & 4.6713 & 80.75 & 3.8536 & -3722.85 & -2112.4 \\
29 & 87.25 & 10.6337 & 87.00 & 8.9851 & 269.8113 & 45.8 \\
30 & 91.50 & 7.3948 & 91.25 & 4.5596 & -284.781 & -253.9 \\
\hline & & & & & &
\end{tabular}

In the first step, the nonlinear static problem was solved by modelling the cables with the use of tension only cut-off bars. Two types of loads were considered: the bridge without any additional mass and after introduction of discrete mass near the point of the first cable fastening (in the middle of span). Taking into account initial static stresses, the first natural

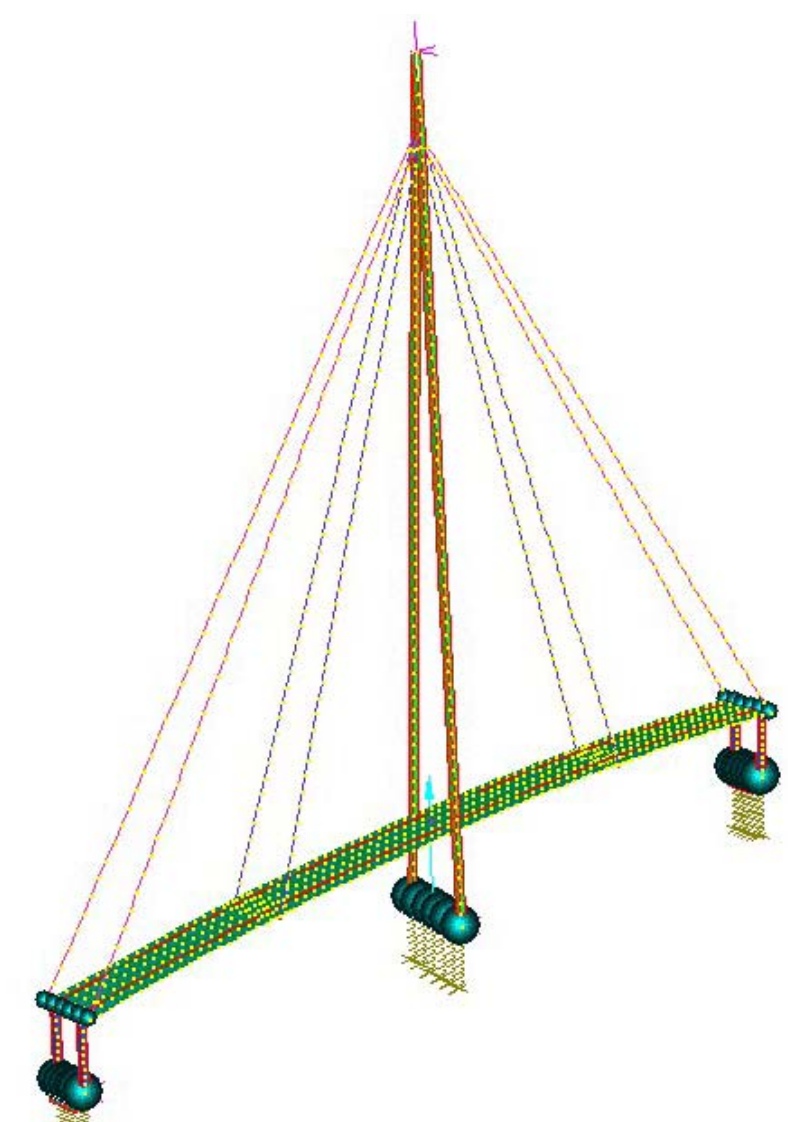

Fig. 10 Created finite elements model of the suspension bridge.

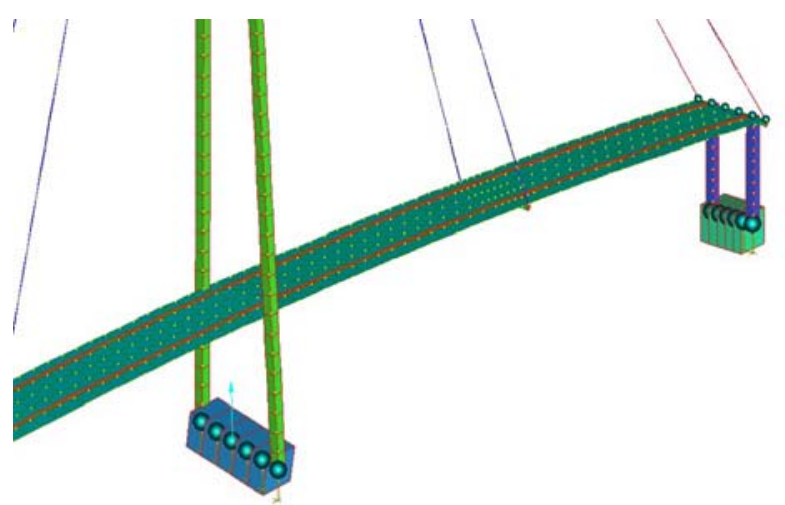

Fig. 11 Bridge span-model created with the use of the finite elements method. 
Table 4 Parameters of transfer function and system parameters determined on the basis of the FEM.

\begin{tabular}{|c|c|c|c|c|}
\hline No. & $f(\mathrm{~Hz})$ & $f^{\prime}(\mathrm{Hz})$ & $\left\{T_{21}^{\prime}\right\}$ & $\begin{array}{l}M_{\mathrm{Z}} \\
(\mathrm{kg})\end{array}$ \\
\hline 1 & 0.054564 & 0.054564 & $18.327210-612,300.00$ & 0.00 \\
\hline 2 & 0.054567 & 0.054567 & $18.3262133,271,650.38$ & 185.13 \\
\hline 3 & 0.054568 & 0.054568 & $18.325849-16,754,632$ & 185.13 \\
\hline 4 & 0.054569 & 0.054569 & $18.325288-812,560.25$ & 185.13 \\
\hline 5 & 0.054570 & 0.054570 & $18.325087-1.5172736$ & 34.53 \\
\hline 6 & 0.054570 & 0.054570 & $18.324976-13.4567$ & 130.85 \\
\hline 7 & 0.054570 & 0.054570 & $18.324975-98,224.299$ & 185.12 \\
\hline 8 & 0.054570 & 0.054570 & $18.324967-32,608.135$ & 185.09 \\
\hline 9 & 0.075208 & 0.075208 & $13.296501-10,518.666$ & 185.03 \\
\hline 10 & 0.075208 & 0.075208 & $13.296474-8046.4568$ & 184.99 \\
\hline$\ldots$ & & & & \\
\hline 101 & 1.353986 & 1.353986 & $0.7385600-3,253.7522$ & 184.81 \\
\hline 102 & 1.400780 & 1.400771 & $0.713892635,267.9765$ & 185.12 \\
\hline 103 & 1.401700 & 1.401700 & $0.7134192-8,157,955.2$ & 185.13 \\
\hline 104 & 1.401779 & 1.401778 & $0.7133796-375.37476$ & 182.21 \\
\hline 105 & 1.401785 & 1.401785 & $0.7133761-22.755641$ & 148.30 \\
\hline 106 & 1.401797 & 1.401797 & $0.7133700-412,225.87$ & 185.13 \\
\hline 107 & 1.401802 & 1.401802 & $0.71336731,617.30992$ & 185.75 \\
\hline 108 & 1.401818 & 1.401818 & $0.7133594-926,770.3$ & 185.13 \\
\hline 109 & 1.401819 & 1.401819 & $0.7133588-22,648.137$ & 185.08 \\
\hline 110 & 1.527711 & 1.527391 & $0.6547113-0.0012792$ & 1.29 \\
\hline$\ldots$ & & & & \\
\hline 151 & 2.653387 & 2.653387 & $0.3768768-2,233.5721$ & 184.67 \\
\hline 152 & 2.65339 & 2.65339 & $0.37687642,517,379.2$ & 185.13 \\
\hline 153 & 2.653396 & 2.653396 & $0.37687553,739,935.86$ & 185.13 \\
\hline 154 & 2.653457 & 2.653457 & $0.3768669-45.822044$ & 165.01 \\
\hline 155 & 2.655375 & 2.655358 & $0.3765971-3207.7116$ & 184.82 \\
\hline 156 & 2.659093 & 2.659081 & 0.3760698261 .479729 & 189.47 \\
\hline 157 & 2.83449 & 2.828334 & $0.353565 \quad 276.620019$ & 180.99 \\
\hline 158 & 2.890432 & 2.885138 & $0.3466038-0.1181863$ & 3.55 \\
\hline 159 & 2.894665 & 2.894501 & $0.3454827-0.0293499$ & 4.51 \\
\hline 160 & 2.912882 & 2.911404 & 0.343476910 .8197695 & 407.69 \\
\hline$\ldots$ & & & & \\
\hline 301 & 9.021716 & 9.021693 & $0.1108439-254,672.12$ & 185.09 \\
\hline 302 & 9.023906 & 9.023906 & $0.1108168937,368.285$ & 185.14 \\
\hline 303 & 9.024288 & 9.024284 & $0.1108121-48,321.618$ & 185.10 \\
\hline 304 & 9.129262 & 9.129265 & $0.1095378-4,500.5966$ & 184.90 \\
\hline 305 & 9.129447 & 9.129459 & $0.1095355-24,488.108$ & 185.03 \\
\hline 306 & 9.129512 & 9.129513 & 0.1095349601 .146432 & 187.00 \\
\hline 307 & 9.129514 & 9.129515 & $0.10953482,234.45402$ & 185.62 \\
\hline 308. & 9.12957 & 9.12957 & $0.109534229,081.9064$ & 185.17 \\
\hline 309. & 9.130841 & 9.1308 & $0.1095194-26,284.538$ & 185.08 \\
\hline 310. & 9.131321 & 9.131345 & $0.1095129-411.05741$ & 182.50 \\
\hline
\end{tabular}
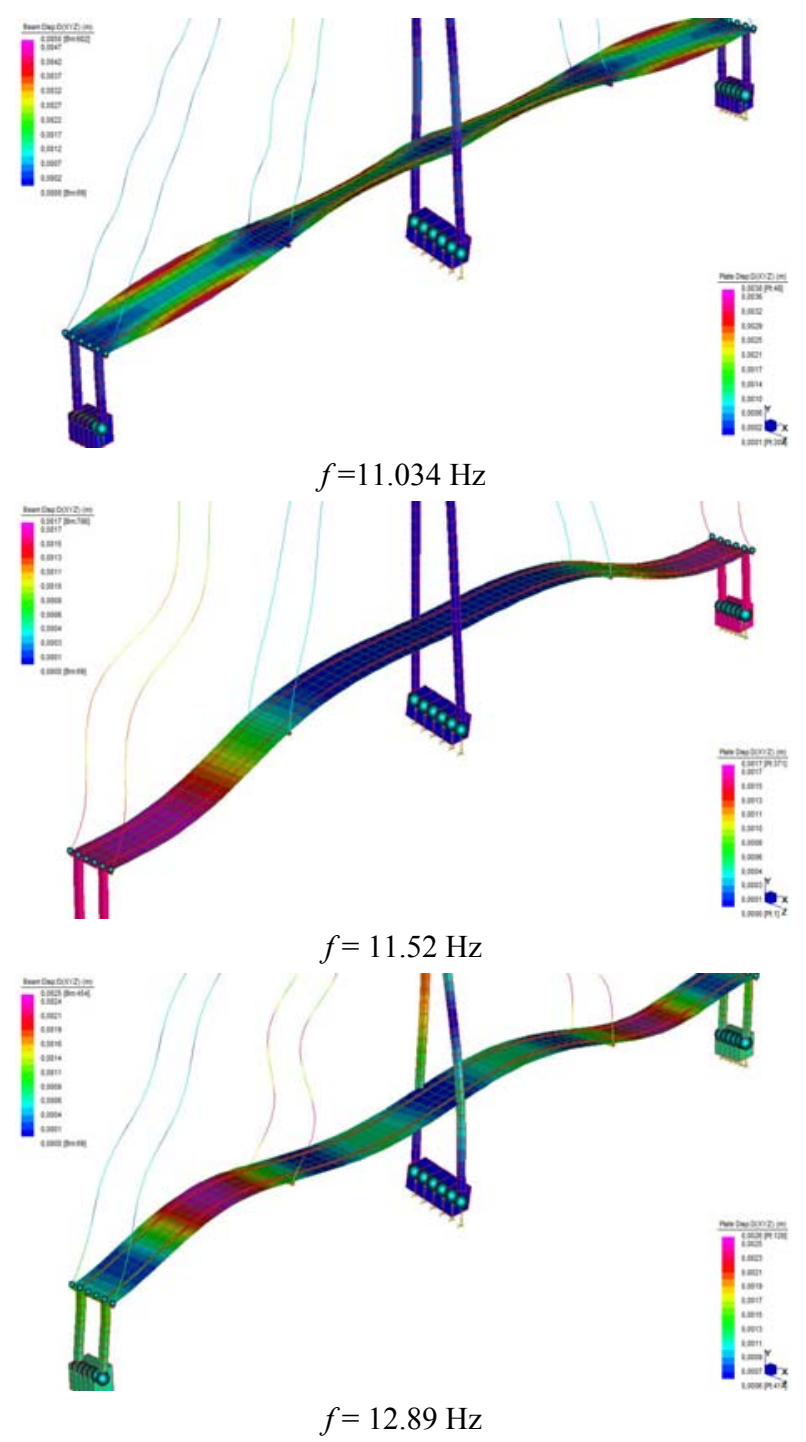

Fig. 12 Selected mode shapes of the considered suspension bridge estimated with the use of the finite elements method.

frequencies of construction without and with an additional mass introduced were estimated.

Having applied exciting force of spectral density constant in the frequency range $0-12 \mathrm{~Hz}$, transfer functions of construction before $\left\{T_{21}\right\}$ and after introduction of an additional mass $\left\{T_{21}\right.$ ' $\}$ were determined. Values of resonant frequencies and corresponding magnitudes of the considered transfer functions are gathered in Table 4. In the last column, the values of the estimated reduced mass $M_{Z}$ are presented. Selected mode shapes of the considered suspension bridge, estimated with the use of the finite elements method, are gathered in Figs. 12 and 13. 


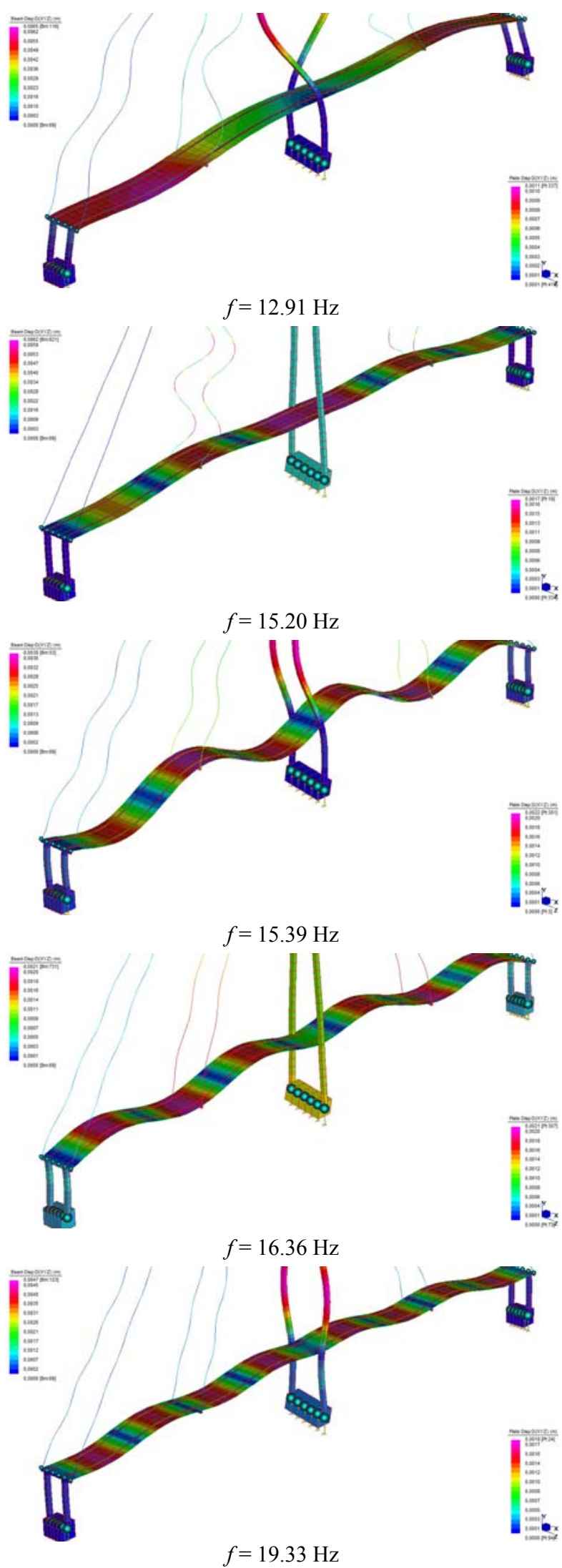

Fig. 13 Selected mode shapes of the considered suspension bridge estimated with the use of the finite elements method.

\section{Conclusions and Final Remarks}

The paper concerns research into dynamic properties of the steel suspension bridge in Krakow, Poland. Identification of system parameters was carried out by means of the output-only nonlinear system identification method, on the basis of system responses to exploitational excitation, resulting from pedestrian traffic. In order to verify the correctness of the obtained results, on the basis of the geometrical and material properties of the considered system, the FEM was created. Created FEM was updated through the comparison with model determined by the use of experimental modal analysis method and then applied to analytical evaluation of the considered suspension bridge natural frequencies.

Taking into account considerable bridge mass and stiffness, exploitational excitation resulting from pedestrian traffic seems to be insufficient for the purposes of analysis of the considered system dynamic properties. Proper excitation of system mode shapes requires application of an additional excitation provided by the shaker.

Restoring force method can be used for the purposes of nonlinearity detection in systems of continuous mass distribution.

Linear properties of the considered bridge prove its good technical states (e.g., lack of clearances, cracks).

\section{References}

[1] Kerschen, G., Worden, K., Vakakis, A. F., and Golinval, J. C. 2006. "Past, Present and Future of Nonlinear System Identification in Structural Dynamics." Mech. Systems and Signal Processing 20: 505-92.

[2] Haroon, M., Adams, D. E., Luk, Y. W., and Ferri, A. A. 2005. "A Time and Frequency Domain Approach for Identifying Nonlinear Mechanical System Models in the Absence of an Input Measurement." Journal of Sound and Vibration 283: 1137-55.

[3] Iwaniec, J. 2009. Selected Issues of Nonlinear Systems Identification Methods. Radom: ITE (Institute of Transportation Engineers).

[4] Iwaniec, J., and Uhl, T. 2006. "Output-only Technique for Estimation of Nonlinear System Parameters for In-flight Test Application, Noise and Vibration Engineering." In 
the Proceedings of ISMA 2006, 1589-602.

[5] Iwaniec, J., and Uhl, T. 2007. "Identification of Nonlinear Parameters of the Skytruck Airplane Landing Gear by Means of the Operational Modal Analysis Output-Only Method." Molecular and Quantum Acoustics 28: 113-24.

[6] Iwaniec, J. 2013. "Identification of Car Suspension System Parameters on the Basis of Exploitational Measurements." Diagnostyka 14 (2): 11-6.

[7] Masri, S. F., and Caughey, T. K. 1979. "A Nonparametric Identification Technique for Nonlinear Dynamic Problems.” Journal of Applied Mechanics 46: 433-47.

[8] Crawley, E. F., and O'Donnell, K. J. 1986. "Identification of Nonlinear System Parameters in Joints Using the Force-State Mapping Technique.” AIAA Paper 86 (1013): 659-67.

[9] Crawley, E. F., and Aubert, A. C. 1986. "Identification of Nonlinear Structural Elements by Force-State Mapping." AIAA Journal 24: 155-62.

[10] Duym, S., Schoukens, J., and Guillaume, P., 1996. "A Local Restoring Surface Method." International Journal of Analytical and Experimental Modal Analysis 11: 116-32.

[11] Masri, S. F., and Caughey, T. K. 1979. "A Nonparametric
Identification Technique for Nonlinear Dynamic Problems." Journal of Applied Mechanics 46: 433-47.

[12] Bouc, R. 1967. "Forced Vibrations of Mechanical Systems with Hysteresis." Presented at the 4th Conference on Non-linear Oscillations, Prague, Czech.

[13] Wen, Y. K. 1976. "Method for Random Vibration of Hysterstic Systems." Journal of Engineering Mechanics Division 102 (2) 249-63.

[14] Benedettini, F., Capecchi, D., and Vestroni, F. 1991. Nonparametric Models in Identification of Hysteretic Oscillators. Report DISAT N.4190, Dipartimento di Ingegneria delle Strutture, Universita' dell'Aquila, Italy.

[15] Lo, H. R. and Hammond, J. K. 1988. Identification of a Class of Nonlinear Systems. Southampton: Institute of Sound and Vibration Research.

[16] Available online at: http://www.footbridge.pl.

[17] Bednarz, J., Szwedo, M., and Mendrok, K. 2009. Experimental Modal Analysis of the Footbridge over Opolska Street in Krakow. Report of AGH University of Science and Technology.

[18] Strand7 Software Theoretical Manual, Theoretical background to the Strand7 finite element analysis system, available online at: http://www.strand7.com. 